ORIGINAL ARTICLE

\title{
Application of Prechtl's Method on the Qualitative Assessment of General Movements to Predict Neuromotor Outcomes of Premature Babies at one year Corrected Age - Study from a Clinical Facility in Dubai
}

\author{
${ }^{{ }^{*}}$ Thanooja Naushad \\ ${ }^{2} \mathrm{~N}$ Meena \\ ${ }^{3}$ Tushar Vasant Kulkarni \\ ${ }^{4}$ Noel George
}

\begin{abstract}
Background and purpose: Prechtl's general movement assessment is a tool to identify infants at risk of abnormal neurodevelopmental outcomes especially cerebral palsy. There is a need for further studies to establish its effectiveness in clinical practice. The main objective of this study was to find the diagnostic accuracy of prechtl's general movement assessment to predict neuromotor outcomes of preterm babies at one year corrected age when done in a standard clinical practice setting. The secondary objective was to find the inter-rater reliability of general movement assessment between two raters in a clinical setting.

Methods: 116 preterm infants (55 females and 61 males) born below gestational age 35 weeks participated in this study. Prechtl's general movement assessment was done at two points of time - once between 33 to 40 weeks post menstrual age and later between 3to4 months corrected age. Babies were reassessed at 12 months ( \pm 1 week) corrected age using the Infant Neurological International Battery and Alberta Infant Motor Scale to identify neuromotor dysfunction. To find the inter-rater reliability, 75 video recordings at preterm/term age and 73 recordings at fidgety age were viewed and rated independently by two raters.

Results: Statistical analysis using the Fishers' exact test and Pearson's chi-square test showed significant association $(\mathrm{p}<.001)$ between Prechtl's General movement assessment and neuromotor outcomes at one year corrected age. General movement assessment at preterm age and fidgety age showed sensitivity of $85 \%$ (each), specificity of $85 \%$ \& $99 \%$, positive predictive value of $27 \%$ \& $85 \%$, and negative predictive value of $98 \%$ \& $99 \%$ respectively in predicting neuromotor outcomes. Substantial agreement was found between two trained raters. Kappa values were 0.78 and 0.72 for assessments done at preterm/ term age and three months corrected age respectively.

Conclusion: The results suggest that Prechtl's general movement assessment done in routine clinical settings can reliably predict neuromotor outcomes of premature babies at one year corrected age. Thus, it has practical applications to identify premature babies at high risk of abnormal neurodevelopment in infancy.
\end{abstract}

Keywords: Fidgety movements, General Movement Assessment, Neuromotor Outcome, Preterm.

Received $21^{\text {st }}$ September 2020, accepted $02^{\text {nd }}$ March 2021, published $09^{\text {th }}$ March 2021

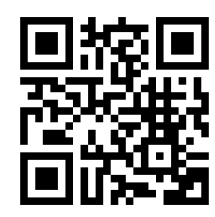

DOI: $10.15621 /$ ijphy/2021/v8i1/897

www.ijphy.org

\footnotetext{
${ }^{2}$ Lecturer, Physical Medicine and Rehabilitation

Annamalai University, Chidambaram, India.

Email: roshmena@gmail.com

${ }^{3}$ Senior Specialist Registrar, Neonatology

Latifa Women and Children Hospital, Dubai, UAE.

Email: tushardips@yahoo.com

${ }^{4}$ Biostatistician, Pvalue solutions, Pala, Kerala.

Email: noel@pvalue.co.in
}

\section{CORRESPONDING AUTHOR}

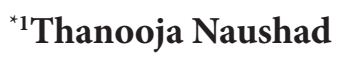

Senior Physiotherapist,

Latifa Women and Children Hospital, Dubai,

UAE. P O Box 9115.

Email: thanuphysio@gmail.com 


\section{INTRODUCTION}

Infants born very premature, including those born later than 32 weeks gestation, are at increased risk of adverse neurodevelopmental impairments (Duncan \& Matthews, 2018[1]; Torchin, Morgan \& Ancel, 2020 [2]). Hence, early identification of preterm babies with a high risk for future neurological deficits is essential to streamline early intervention services. There are many neurological and neuromotor assessment tools currently available to examine premature babies before discharge from the neonatal intensive care unit, one of which is the Prechtl's General movement assessment.

General movements are motor patterns endogenously generated by the nervous system and are an essential functional indicator of brain function in the fetus, preterm, and term infants (Einspieler et al., 2004) [3]. If the nervous system is impaired, there will be changes in quality of general movements. Depending on the infant's age, it may manifest as one of the following abnormal patterns: poor repertoire, cramped synchronized, chaotic or absent/ abnormal fidgety movements (Einspieler et al., 2004) [3]. Research shows that abnormal general movements before term and at term are associated with poor motor and neurological outcomes at 12 months corrected age in children born preterm (Olsen et al., 2018). [4]. If fidgety movements are abnormal, absent, or sporadic, it indicates an increased risk for later neurological dysfunction, whereas normal fidgety movements are highly predictive of normal outcomes (Adde et al., 2007[5]; Einspieler et al., 2012[6]; Kwong et al.,2018[7]).

One criticism regarding the general movement assessment is that most of the studies on general movements were done by highly experienced trainers in specific research settings that may not reflect common hospital practice conditions (Øberg, Jacobsen \& Jørgensen, 2015) [8]. Specific video recording arrangements (Einspieler et al., 2004) [3], multiple serial assessments before discharge from neonatal intensive care unit (Einspieler et al., 2016 [9]; Ferrari et al ., 2002 [10]) or prolonged duration of video recordings (Ferrari, Cioni \& Prechtl,1990) [11] are also not practical in routine clinical practice. Another criticism regarding general movements is the selective inclusion of high-risk preterm infants and subsequently increased manifestation of cerebral palsy (Snider et al., 2008) [12]. General movement studies are mostly reported from European countries, and there is limited research from other countries (Tomantschger et al.,2018) [13]. Though there are some studies on general movements based on clinical settings, there is a need for further evidence regarding its effectiveness in predicting neuromotor outcomes, especially in early infancy.

The primary objective of this study was to investigate whether general movement assessment done in a routine clinical setting at 2 points of time (i.e., between 33 to 40 weeks postmenstrual age and between 3 to 4 months corrected age) using a short video recording can predict compromised neuromotor function at one year corrected age. The secondary objective was to find the general movement assessment's inter-rater reliability in a clinical setting.

\section{METHODS}

\subsection{Study Design and Subjects}

One hundred sixteen babies born between January 2018 to March 2019 and admitted to the neonatal intensive care unit of Latifa Women and Children hospital, Dubai, participated in this prospective cohort study. Inclusion criteria was being born at gestational age $<35$ weeks and with birth weight $<2.5 \mathrm{~kg}$. Babies with genetic syndromes or any congenital anomalies were excluded. Ethical approval was obtained (DSREC-SR-08/2017_04) from the Dubai Scientific Research and Ethics committee of Dubai Health Authority. Signed informed consent was obtained from parents who agreed to enroll their babies in the study.

\subsection{Study Procedure}

All babies underwent general movement assessment between 33 to 40 weeks postmenstrual age before discharge from the neonatal intensive care unit. For this initial assessment, babies were suitably undressed and positioned supine after all positioning supports were removed. A commercial handheld video camera was used for video recording. Investigator stood at the foot end of the crib/ incubator and recorded baby movements for up to 5 minutes when the babies were in a state of active wakefulness. The second general movement assessment was conducted in the outpatient physiotherapy department of Latifa Hospital when the babies were 3 to 4 months corrected age. All distracting toys were removed from infant's vicinity, and parents were requested not to engage the infant during the assessment duration. Video recording was done when the infants were in a quiet alert or active alert state. Thus each infants had two video recordings- one taken before discharge from the neonatal intensive care unit and one done around three to four months corrected age. These videos were played back in a computer at normal speed, and movement categorizations were done as normal or abnormal based on specific criteria (Einspieler et al., 2004) [3].

General movement assessment done between 33-40 weeks were classified as normal repertoire when normal preterm general movements were noticed, poor repertoire when movement components were monotonous, crampedsynchronized when the limb and trunk muscles contracted and relaxed almost simultaneously \& chaotic when movements appeared jerky and abrupt. General movement assessment done at 3 to 4 months corrected age was categorized as normal fidgety when fidgety movements were present and normal, absent fidgety when fidgety movements were sporadic or absent \& abnormal fidgety when the amplitude/speed of fidgety movement was exaggerated.

Infants were brought for final follow-up at 12 months corrected age $( \pm 1$ week) and were assessed using the Infant Neurological International Battery- INFANIB (Ellison, 
1994) [14] and the Alberta Infant Motor Scale-AIMS (Piper\&Darrah,1994) [15]. An infant with an INFANIB score of $\leq 82$ at 12 months corrected age and whose score was below 5 th centile on the AIMS was considered to have abnormal neuromotor outcome. Statistical analysis was done using SPSS software version 21. Fisher's exact test and Pearson's chi-square test were used to determine whether the results of general movement assessment was associated with neuromotor outcomes at one year corrected age. Sensitivity, specificity, positive, and negative predictive values were calculated to find the diagnostic accuracy of general movements. To find the inter-rater reliability, a 2nd rater who was blinded to the medical history of study population reviewed and categorized 75 GMA videos recorded at preterm/ term age and 73 videos recorded at fidgety age. Kappa values were generated to explain the inter-rater reliability in the assessment.

\section{RESULTS}

Relevant demographic and clinical characteristics of the 116 preterm babies who completed this

the study is given in Table 1.

Table 1: Demographic and clinical characteristics of participants

\begin{tabular}{|c|c|c|c|}
\hline Category & Type & Frequency & Percentage (\%) \\
\hline \multirow{2}{*}{ Sex } & Female & 55 & 47.4 \\
\cline { 2 - 4 } Gestational Age & Male & 61 & 52.6 \\
\cline { 2 - 4 } & $\leq 28$ & 16 & 13.8 \\
\cline { 2 - 4 } & $28-32$ & 65 & 56 \\
\hline Birth Weight & $<32$ & 35 & 30.2 \\
\hline $\begin{array}{c}\text { Bronchopulmonary } \\
\text { Dysplasia }\end{array}$ & Present & 71 & 61.2 \\
\hline Brain Ultrasound & Abnormal & 28 & 15.5 \\
\hline
\end{tabular}

The mean age of initial general movement assessment was at a postmenstrual age of 35.82 weeks (SD 1.96). During the initial general movement assessment, abnormal repertoive of movements were observed in 22 babies. Chaotic movements were not observed in any baby at this stage. Among infants with abnormal repertoire, seven infants $(31.8 \%)$ were born at $<28$ weeks gestation, ten infants $(45.5 \%)$ were born at $28-<32$ weeks gestation, and five infants (22.7\%) were born at $\geq 32$ weeks. Six of the 22 infants with abnormal repertoire movements also had abnormal neuromotor outcomes at a one-year corrected age.

Follow-up assessment was done at a mean age of 3.01 months corrected age (SD .47). In this follow-up, absent or sporadic fidgety movements were noticed in a total of 7 babies, of whom six babies were found to have compromised neuromotor functioning when assessed using INFANIB and AIMS at one year corrected age. Six of the seven infants with absent / sporadic fidgety movements were born at gestational age $<30$ weeks. The presence of abnormal fidgety movements was not noticed in any baby during the follow-up at three months. In the final follow up a total of seven infants showed transiently abnormal or abnormal scores in INFANIB. 18 babies had scored less than 5 th centile on the AIMS at 12 months corrected age. However, only those who also had transiently abnormal or abnormal score in INFANIB $\leq 82$ were considered in the final tally of babies with neuromotor dysfunction. It was observed that all babies with compromised neurological function in the INFANIB had AIMS scores below the $5^{\text {th }}$ centile. Of the 94 babies with normal repertoire of movements at 33-40 weeks only one infant had compromised neuromotor function at 12 months. Similarly, of the 109 infants with normal fidgety movements, only one infant showed neuromotor dysfunction at 12 months.

Probability testing with Fisher's exact test and Pearson's Chi-square test indicated a significant association between GMA and the neuromotor outcomes at a one-year corrected age. This is shown in tables 2 and 3.

Table 2: Association of prechtl's General movement assessment at preterm/term age with neuromotor outcomes measured using INFANIB and AIMS

\begin{tabular}{|c|c|c|c|c|c|}
\hline \multirow{2}{*}{\multicolumn{2}{|c|}{ Variables }} & \multicolumn{2}{|c|}{$\begin{array}{l}\text { GMA at preterm / } \\
\text { term age }\end{array}$} & \multirow{3}{*}{$\begin{array}{c}\text { Total } \\
98\end{array}$} & \multirow{3}{*}{ p-value } \\
\hline & & \multirow{2}{*}{$\begin{array}{c}\begin{array}{c}\text { Normal } \\
\text { Reper- } \\
\text { toire }\end{array} \\
86\end{array}$} & \multirow{2}{*}{$\begin{array}{c}\text { Abnormal } \\
\text { Repertoire }\end{array}$} & & \\
\hline \multirow{4}{*}{$\begin{array}{l}\text { AIMS } \\
\text { centile } 12 \\
\text { months (a) }\end{array}$} & \multirow{2}{*}{$\begin{array}{l}\text { On or above } \\
5 \text { th centile }\end{array}$} & & & & \\
\hline & & $87.8 \%$ & $12.2 \%$ & & \multirow{3}{*}{$<0.001^{\star *}$} \\
\hline & \multirow{2}{*}{$\begin{array}{l}\text { Below 5th } \\
\text { centile }\end{array}$} & 8 & 10 & 18 & \\
\hline & & $44.4 \%$ & $55.6 \%$ & & \\
\hline \multirow{4}{*}{$\begin{array}{l}\text { INFANIB }^{(2)} \\
\text { Category }^{(b)}\end{array}$} & \multirow{2}{*}{ Normal } & 93 & 16 & 109 & \multirow{4}{*}{$<0.001^{\star *}$} \\
\hline & & $85.3 \%$ & $14.7 \%$ & & \\
\hline & \multirow{2}{*}{$\begin{array}{c}\text { Transiently } \\
\text { abnormal or } \\
\text { abnormal }\end{array}$} & 1 & 6 & 7 & \\
\hline & & $14.3 \%$ & $85.7 \%$ & & \\
\hline
\end{tabular}

** Significant at $1 \%$ level of significance

(a) Pearson's chi-square test

(b) Fisher's exact test

Table 3: Association of General movement assessment at three months with neuromotor outcomes measured using INFANIB and AIMS

\begin{tabular}{|c|c|c|c|c|c|}
\hline \multirow{2}{*}{\multicolumn{2}{|c|}{ Variables }} & \multicolumn{2}{|c|}{ GMA at 3 months } & \multirow{3}{*}{$\begin{array}{c}\text { Total } \\
98\end{array}$} & \multirow{3}{*}{$\mathrm{p}$ value } \\
\hline & & \multirow{2}{*}{$\begin{array}{c}\text { Normal } \\
\text { Fidgety }\end{array}$} & \multirow{2}{*}{$\begin{array}{c}\text { Absent or } \\
\text { Sporadic } \\
\text { Fidgety }\end{array}$} & & \\
\hline \multirow{4}{*}{$\begin{array}{c}\text { AIMS } \\
\text { at } 12 \\
\text { months }^{(a)}\end{array}$} & \multirow{2}{*}{$\begin{array}{l}\text { On or above } \\
\text { 5th centile }\end{array}$} & & & & \\
\hline & & $99.0 \%$ & $1.0 \%$ & & \multirow{3}{*}{$<0.001^{\star *}$} \\
\hline & \multirow{2}{*}{$\begin{array}{l}\text { Below 5th } \\
\text { centile }\end{array}$} & 12 & 6 & 18 & \\
\hline & & $66.7 \%$ & $33.3 \%$ & & \\
\hline \multirow{4}{*}{$\begin{array}{l}\text { INFANIB } \\
\text { Catego- } \\
\text { ry }{ }^{\text {(a) }}\end{array}$} & \multirow{2}{*}{ Normal } & 108 & 1 & 109 & \multirow{4}{*}{$<0.001^{\star *}$} \\
\hline & & $99.1 \%$ & $.9 \%$ & & \\
\hline & \multirow{2}{*}{$\begin{array}{c}\text { Transiently } \\
\text { abnormal or } \\
\text { abnormal }\end{array}$} & 1 & 6 & 7 & \\
\hline & & $14.3 \%$ & $85.7 \%$ & & \\
\hline
\end{tabular}

** Significant at $1 \%$ level of significance

(a) Fisher's exact test was used

To find the diagnostic accuracy of GMA the presence 
of poor repertoire patterns /cramped synchronized patterns , absent fidgety \& sporadic fidgety movements was considered to be test positive \& abnormal neuromotor outcome at one year corrected age was considered as disease positive. The diagnostic accuracy of the general movement assessment is shown in table 4.

Table 4: Diagnostic accuracy of general movement assessment with neuromotor outcomes

\begin{tabular}{|c|c|c|c|c|}
\hline \multirow{2}{*}{$\begin{array}{c}\text { Accuracy } \\
\text { Measures }\end{array}$} & \multicolumn{2}{|c|}{ GMA at 33-40 weeks } & \multicolumn{2}{|c|}{ GMA at 3-4 months } \\
\cline { 2 - 5 } Sensitivity & Value & $\mathbf{9 5 \%}$ CI & Value & $\mathbf{9 5 \%}$ CI \\
\hline Specificity & $85.71 \%$ & $\begin{array}{c}42.13 \% \text { to } \\
99.64 \%\end{array}$ & $85.71 \%$ & $\begin{array}{c}42.13 \% \text { to } \\
99.64 \%\end{array}$ \\
\hline $\begin{array}{c}\text { Positive } \\
\text { predictive } \\
\text { value }\end{array}$ & $27.27 \%$ & $\begin{array}{c}77.26 \% \text { to } \\
91.37 \%\end{array}$ & $99.08 \%$ & $\begin{array}{c}94.99 \% \text { to } \\
99.98 \%\end{array}$ \\
\hline $\begin{array}{c}\text { Negative } \\
\text { predictive } \\
\text { value }\end{array}$ & $98.94 \%$ & $\begin{array}{c}93.80 \% \text { to } \\
99.83 \%\end{array}$ & $85.71 \%$ & $\begin{array}{c}45.45 \% \text { to } \\
97.74 \%\end{array}$ \\
\hline $\begin{array}{c}\text { Positive } \\
\text { likelihood } \\
\text { ratio }\end{array}$ & 5.84 & 3.39 to 10.06 & $93.08 \%$ & $\begin{array}{c}94.62 \% \text { to } \\
99.85 \%\end{array}$ \\
\hline $\begin{array}{c}\text { Negative } \\
\text { likelihood } \\
\text { ratio }\end{array}$ & .17 & 0.03 to 1.03 & 0.14 & $\begin{array}{c}12.97 \text { to } \\
672.83\end{array}$ \\
\hline $\begin{array}{c}\text { Disease } \\
\text { Prevalence }\end{array}$ & $6.03 \%$ & $\begin{array}{c}2.46 \% \text { to } \\
12.04 \%\end{array}$ & $6.03 \%$ & $\begin{array}{c}2.46 \% \text { to } \\
12.04 \%\end{array}$ \\
\hline $\begin{array}{c}\text { Accuracy } \\
\text { nyyyy}\end{array}$ & $85.34 \%$ & $\begin{array}{c}77.58 \% \text { to } \\
91.22 \%\end{array}$ & $98.28 \%$ & $\begin{array}{c}93.91 \% \text { to } \\
99.79 \%\end{array}$ \\
\hline
\end{tabular}

\section{Inter-rater reliability of GMA}

Cohen's Kappa was calculated to determine if there was an association between two raters on categorizing general movements at preterm/term age and 3-4 months corrected age. The frequency distribution for the inter-rater reliability assessment is shown in table 5 .

Table 5: Frequency distribution for calculation of interrater reliability of General Movement Assessment

\begin{tabular}{|c|c|c|c|c|c|}
\hline \multirow{2}{*}{$\begin{array}{c}\text { Assess- } \\
\text { ment }\end{array}$} & \multirow{2}{*}{\multicolumn{2}{|c|}{ Rating }} & \multicolumn{2}{|c|}{ Rater2 } & \multirow{3}{*}{$\begin{array}{c}\text { Total } \\
55 \\
(73.3 \%)\end{array}$} \\
\hline & & & 1 & 2 & \\
\hline \multirow{3}{*}{$\begin{array}{c}\text { GMA Pre } \\
\text { Term/Term } \\
\text { age }\end{array}$} & \multirow{2}{*}{ Rater1 } & $1^{\mathrm{a}}$ & $\begin{array}{c}54 \\
(72.0 \%)\end{array}$ & $\begin{array}{c}1 \\
(1.3 \%)\end{array}$ & \\
\hline & & $2^{\mathrm{b}}$ & $\begin{array}{c}5 \\
(6.7 \%)\end{array}$ & $\begin{array}{c}15 \\
(20.0 \%)\end{array}$ & $\begin{array}{c}20 \\
(26.7 \%)\end{array}$ \\
\hline & \multicolumn{2}{|c|}{ Total } & $\begin{array}{c}59 \\
(78.7 \%)\end{array}$ & $\begin{array}{c}16 \\
(21.3 \%)\end{array}$ & $\begin{array}{c}75 \\
(100.0 \%)\end{array}$ \\
\hline \multirow{3}{*}{$\begin{array}{l}\text { GMA } \\
\text { Fidgety of } \\
\text { age }\end{array}$} & \multirow{2}{*}{ Rater1 } & $1^{\mathrm{c}}$ & $63(86.3 \%)$ & $1(1.4 \%)$ & $\begin{array}{c}64 \\
(87.7 \%)\end{array}$ \\
\hline & & $2^{\mathrm{d}}$ & $\begin{array}{c}3 \\
(4.1 \%)\end{array}$ & $\begin{array}{c}6 \\
(8.2 \%)\end{array}$ & $\begin{array}{c}9 \\
(12.3 \%)\end{array}$ \\
\hline & \multicolumn{2}{|c|}{ Total } & $\begin{array}{c}66 \\
(90.4 \%)\end{array}$ & $\begin{array}{c}7 \\
(9.6 \%)\end{array}$ & $\begin{array}{c}73 \\
(100.0 \%)\end{array}$ \\
\hline
\end{tabular}

a: 1 denotes normal repertoire ${ }^{\mathrm{b}} 2$ denotes abnormal repertoire
${ }^{c} 1$ denotes normal fidgety fidgety

From the frequency distribution as shown in table 5 kappa values were calculated. This is shown in table 6 .

Table 6: Inter-rater reliability of General movement assessment

\begin{tabular}{|c|c|c|c|c|c|}
\hline Test & $\begin{array}{c}\text { Measure of } \\
\text { Agreement }\end{array}$ & Value & $\begin{array}{c}\text { Asymptotic } \\
\text { Std. Error }\end{array}$ & t statistic & p-value \\
\hline $\begin{array}{c}\text { GMA at } \\
\text { preterm/ } \\
\text { term age }\end{array}$ & Kappa & .782 & .084 & 6.841 & $<0.001^{\star *}$ \\
\hline $\begin{array}{c}\text { GMA at } \\
3-4 \text { months } \\
\text { corrected } \\
\text { age }\end{array}$ & Kappa & 0.720 & 0.132 & 6.211 & $<0.001^{\star *}$ \\
\hline
\end{tabular}

\section{DISCUSSION}

The main objective of this study was to investigate whether general movement assessment done in a hospital setting can predict neuromotor outcomes of preterm infants at one year corrected age. This study, a first of its kind from a clinical setting in Dubai, attempted to address some of the factors attributed as the drawbacks of the general movement assessment. In this study, we did not do multiple assessments and limited the video recordings to two-time points - one before discharge from the NICU and one at fidgety age. We did the initial general movement assessment at 33-40 weeks postmenstrual age because most babies from our hospital are discharged between this age range and as some studies have reported that general movement assessment at very early preterm age is likely to demonstrate poor repertoire patterns (de Vries \& Bos, 2010) [16]. We included a more representative sample of preterm infants in our study. The results reflect the diagnostic accuracy of general movement assessment on a broad spectrum of preterm babies with variability in gestational ages and birthweights. Instead of an elaborate recording arrangement, short video clips of up to 5 minutes duration were recorded using a handheld video camera. We also used standardized outcome measures to assess neuromotor function at one year of age, thereby ensuring the replicability of this study by other researchers. Our study results indicate statistically significant association between Prechtl's general movement assessment and neuromotor outcomes of premature infants at one year corrected age. Results also indicate that babies born very preterm ( $<32$ weeks gestation) were most likely to develop abnormal movement repertoire in the GMA.

Among the 22 babies with abnormal repertoire of movements in the initial assessment, 19 babies (86.36\%) showed poor repertoire movements, of which only six babies had compromised neurological function in the oneyear follow-up. Hence, this study is in agreement with earlier observations that poor repertoire patterns might get normalized towards fidgety age and subsequently has lower predictive value for neurological involvement, including cerebral palsy (Bos, 1998[17]; Nakajima et al .,2006 [18]). It can be reasoned that using general movements as the only assessment tool for premature babies in the neonatal unit may not be sufficient to identify those preterm infants 
who require early intervention services. Integrated use of a neurological examination and general movement improves early prediction of neurodevelopmental outcomes, as is shown in earlier studies (Burger \& Louw, 2009 [19]; Romeo et al., 2008 [20]).

Our results are similar to several previous studies which reported that the absence of fidgety movements is associated with poor neurological outcomes, and normal fidgety movements are associated with a low risk of neurological dysfunction (Bosanquet et al ., 2013[21]; Darsaklis et al., 2011[22]). General movements at fidgety age have higher diagnostic accuracy for later cerebral palsy as compared to assessment at earlier ages (Kwong et al ., 2018[7]; Sustersic, Sustar \&Paro-Panjan,2012 [23]). Similarly this study also showed that compared to general movement assessment done at preterm / term age, fidgety age assessment showed higher specificity, positive and negative predictive values, and test accuracy for neuromotor outcomes at one year. Compared to some other studies which have reported sensitivity of GMA as $>92 \%$ (Burger \& Louw, 2009 [19]; Kwong et al., 2018[7]; Morgan et al.,2016 [24]), this study indicates lower sensitivity values for absent fidgety movements when the neuromotor outcomes at 12 months corrected age is considered. This could be attributed to the early age of outcome measurement and fewer percentage of extremely preterm infants $(13.8 \%)$ included in this study. It is an established fact that babies born at lower gestational ages have higher chances of neurological impairment in early childhood (Moore et al., 2012) [25]. Most general movement studies have done outcome measurement at two years or above (Adde et al., 2007 [5 ]; Ferrari et al., 2002[10]; Øberg, Jacobsen \& Jørgensen, 2015 [8]). Early follow-up at 1 yer corrected age might not have identified some disease positive cases as mild neurological signs may not be evident at this early age.

There are only limited studies on general movement assessment done in clinical settings (Adde et al.,2007 [5]; Øberg, Jacobnsen \& Jørgensen, 2015[8]; Stoen et al ., 2019 ) [26]). Previously, many studies have reported very high sensitivity and specificity values for fidgety movements to predict cerebral palsy. However, some recent studies indicate that these values may not be very high, especially when the assessment is done in clinical settings. One study ( Stoen et al., 2019 [26]) reported lower sensitivity (76.2\%) and specificity $(82.4 \%)$ but a higher negative predictive value $(96.8 \%)$. Similar observations are also reported in another study (Datta et al., 2017[27]). In comparison, our study results show higher specificity and negative predictive value (99\%) of fidgety movements but lower sensitivity values $(85 \%)$ in predicting neuromotor outcomes at one year. Hadders -Algra,2001 [28] reported that babies with abnormal general movements between 2-4 months who do not develop cerebral palsy may show other developmental issues like minor neurological dysfunction, ADHD, etc. This observation finds resonance in our study. Of the seven infants with absent/sporadic fidgety movements, one baby showed early signs of attention deficit hyperactivity disorder (ADHD) at 12 months corrected age. However, motor delay or clear neurological involvement could not be identified using the outcome measures for this infant.

GMA is reported to have very high interrater reliability of 0.85 - 0.94 (Mutlu et al .,2008 [29] ). In this study, we also attempted to find whether similar reliability could be reproduced in clinical practice. In our study, the calculated kappa values showed substantial agreement between raters. Kappa value $>75 \%$ is considered excellent agreement between raters (Katz \& Perenyi, 2016 [30] ). The reliability values in this study were not low $(0.44$ 0.55 ) as reported in some other GMA studies done in clinical setting (Bernhardt et al., 2011 [31] ). It is reported that GMA ratings by 2 raters to reach a consensus will be more effective to accurately clasify the general movement videos (Øberg, Jacobsen \& Jørgensen, 2015[8]). Though two raters were made available in this study, this may not always be practical in the everyday hospital setting and may depend upon availability of trained staff. However, the relatively higher kappa values in this study indicate that trained raters tend to show higher interrater reliability in general movement assessment even in clinical settings.

\section{CONCLUSION}

This study showed that general movement assessment done within the constraints of a standard clinical setting could reliably predict neuromotor outcomes of premature babies at one year corrected age. Fidgety age assessment generally showed better diagnostic accuracy to predict neurological involvement than assessment at preterm/term age. Trained raters showed substantial agreement in rating the GMA videos. This study contributes to the validation of using general movement assessment in a clinical setting. Prechtl's general movement assessment is a useful adjunct clinical assessment tool for neonatal physiotherapists to assess premature babies in the neonatal intensive care units and developmental follow-up clinics.

\section{Limitations of the study}

This study had several limitations. The results of this study indicate that, compared to the number of infants recruited for the study, the number of babies with abnormal general movements was limited. This points to the need for larger sample size or multi-center trials, as pointed out in another study (Porro et al., 2020[32]). Though the $2^{\text {nd }}$ rater was blinded to infants medical history, the principal investigator had prior knowledge of infants' medical condition. Outcome measurement was conducted at one year corrected age - earlier than usually done for other similar studies. For future studies on general movements, the authors recommend longitudinal follow-up of preterm infants until at least three years of age, multi-center trials, and independent testers blinded to the subject's medical history. In the future, it would also be worthwhile to explore the diagnostic accuracy of a combination of Prechtl's general movement and a neuromotor assessment specific to preterm infants within the context of the neonatal intensive care unit. 


\section{ACKNOWLEDGEMENTS}

The authors would like to acknowledge and appreciate the valuable contribution of Mrs. Nawvi Gopalakrishnan, Pediatric physiotherapist currently associated with Kings College hospital, Dubai, UAE.

\section{CONFLICT OF INTEREST}

Authors declare that they have no conflicts of interest

\section{AUTHOR CONTRIBUTIONS}

Thanooja Naushad completed the data collection. Thanooja Naushad, Meena Natarajan, and Tushar Vasant Kulkarni were involved in the study's design, drafting, and final manuscript editing. Noel George conducted the statistical analysis of data and contributed to drafting and editing of the final manuscript. All the authors read and approved the final manuscript.

\section{REFERENCES}

[1] Duncan AF, Matthews M.A. Neurodevelopmental outcomes in early childhood. Clin Perinatol. 2018; 45(3): 377-392

[2] Torchin H, Morgan AS, Ancel PY. International comparisons of neurodevelopmental outcomes in infants born very preterm. Semin Fetal Neonatal Med. 2020; 25(3).

[3] Einspieler C, Prechtl, HFR, Bos AF, Ferrari F, Cioni G. Prechtl's method on the qualitative assessment of general movements in preterm, term and young infant. Cambridge: Mac Keith Press, 2004

[4] Olsen JE, Allinson LG, Doyle LW, Brown NC, Lee $\mathrm{KJ}$, Eeles $\mathrm{AL}$, et al .Preterm and term-equivalent age general movements and 1-year neurodevelopmental outcomes for infants born before 30 weeks gestation. Dev Med Child Neurol. 2018; 60 (1):47-53.

[5] Adde L, Rygg M, Lossius K, Oberg GK, Stoen R. General movement assessment: Predicting cerebral palsy in clinical practice. Early Hum Dev. 2007 ;83(1) $: 13-8$.

[6] Einspieler C, Marschik PB, Bos AF, Ferrari F, Cioni G, Prechtl HFR. Early markers for cerebral palsy: insights from the assessment of general movements. Future Neurol. 2012; 7(6):709-717.

[7] Kwong AKL, Fitzgerald TL, Doyle LW, Cheong JLY, Spittle AJ. Predictive validity of spontaneous early infant movement for later cerebral palsy: a systematic review. Dev Med Child Neurol ,2018;60(5):480-489.

[8] Øberg GK, Jacobsen BK, Jørgensen L. Predictive Value of General Movement Assessment for Cerebral Palsy in Routine Clinical Practice. Phys Ther.2015; 95(11):1489-1495.

[9] Einspieler C, Marschik PB, Pansy J, Scheuchenegger A, Krieber M, Yang $H$, et al. The general movement optimality score: a detailed assessment of general movements during preterm and term age. Dev Med Child Neurol. 2016; 58(4):361-368.

[10] Ferrari F, Cioni G, Einspieler C, Roversi MF, Bos AF, Paolicelli PB, et al. Cramped synchronized general movements in preterm infants as an early marker for cerebral palsy. Arch Pediatr Adolesc Med. 2002; 156(5):460-467.

[11] Ferrari F, Cioni G, Prechtl HFR. Qualitative changes of General Movements in preterm infants with brain lesions. Early Hum Dev.1990; 23(3):193-231.

[12] Snider LM, Majnemer A, Mazar B, Campbell S, Bos AF. A comparison of the general movement assessment with traditional approaches to new born and infant assessment: Concurrent validity. Early Hum Dev. 2008;84: 297-303.

[13] Tomantschger I, Herrero D, Einspieler C, Hamamura C, Voos MC, Marschik PB. The General movement assessment in non- European low -and middle -income countries, Rev Saúde Pública .(2018) ; 52(6).

[14] Ellison PH. The INFANIB: a reliable method for the neuromotor assessment of infants. San Antonio, Texas, United States: Therapy Skill Builders, 1994.

[15] Piper M C, Darrah J. Motor Assessment Of the developing infant Philadelphia, PA: WB Sanders Company,1994.

[16] deVries NK, Bos AF. The quality of general movements in the first ten days of life in preterm infants. Early Hum Dev. (2010); 86(4):225-229.

[17] Bos AF. Analysis of movement quality in preterm infants. Eur J Obstet Gynecol Reprod Biol. 1998; 76(1):117-119.

[18] Nakajima Y, Einspieler C, Marschik PB, Bos AF, Prechtl HFR. Does a detailed assessment of poor repertoire general movements help to identify those infants who will develop normally? Early Hum Dev. 2006; 82(1):53-59.

[19] Burger M, Louw QA.The predictive validity of General Movements a systematic review. Eur J Pediatr Neurol. 2009; 13(5):408-420.

[20] Romeo DM, Guzzetta A, Scoto M, Cioni M, Patusi P, Mazzone D, Romeo MG. Early neurologic assessment in preterm infants: integration of traditional neurological examination and observation of general movements. Eur J Pediatr Neurol. (2008); 12(3):183189.

[21] Bosanquet M, Copeland L, Ware R, Boyd R. A systematic review of tests to predict cerebral palsy in young children. Dev Med Child Neurol.2013; 55(5):418-426.

[22] Darsaklis V, Snider LM, Majnemer A, Mazer B. Predictive validity of Prechtl's method on the qualitative assessment of general movements: a systematic review of evidence. Dev Med Child Neurol. 2011;53(10):896-906.

[23] Sustersic B, Sustar K, Paro-Panjan D. General movements of preterm infants in relation to their motor competence between 5 and 6 years. Eur J Pediatr Neurol. 2012; 16(6):724-729.

[24] Morgan C, Crowle C, Goyen TA, Hardman C, Jackman M, Novak I et al. Sensitivity and specificity of General Movements Assessment for diagnostic accuracy of detecting cerebral palsy early in an Australian 
context. J Pediatr Child Health. 2016; 52(1):54-59.

[25] Moore T, Hennessy EM, Myles J, Johnson SJ, Draper ES, Costloe KL et al. Neurological and developmental outcome in extremely preterm children born in England in 1995 and 2006: the EPICure studies. BMJ. (2012);345:e7961.

[26] Stoen R, Boswell L, Regnier RA, Fjortoft T, GaeblerSpira D, Ihlen E, et al. The predictive accuracy of the General movement assessment for cerebral palsy: A prospective observational study of high risk infants in a clinical follow -up setting. J Clin Med. 2019;8(11): 1790.

[27] Datta AN, Furrer MA, Bernhardt I, Huppi PS, Borradori-Tolsa C, Busher $\mathrm{H} \mathrm{U}$, et al. Fidgety movements in infants born very preterm : predictive value for cerebral palsy in a clinical multicenter setting. Dev Med Child Neurol.2017;59(6):618-624.

[28] Hadders -Algra M. Evaluation of motor function in young infants by means of the assessment of general movements: a review. Pediatr Phys Ther .2001;13(1): 27-36.

[29] Mutlu A, Einspieler C, Marschik PB, Livanelioglu A. Intra-individual consistency in the quality of neonatal general movements. Neonatology. 2008; 93(3):213-6.

[30] Katz JS, Perenyi A. Interrater and Intrarater reliability using Prechtl's method of qualitative assessment of general movements in infants. Int J Pediatr Res. 2016;2:014.

[31] Bernhardt I, Marbacher M, Hilfiker R, Radlinger L. Inter-and intra-observer agreement of Prechtl's method on the qualitative assessment of general movements in preterm, term and young infants. Early Hum Dev, 2011;87(9) : 633-639.

[32] Porro M, Fontana C, Giannì ML, Pesenti N, Boggini T, De Carli A, et al . Early detection of general movements trajectories in very low birth weight infants. Sci Rep. 2020;1013290. 